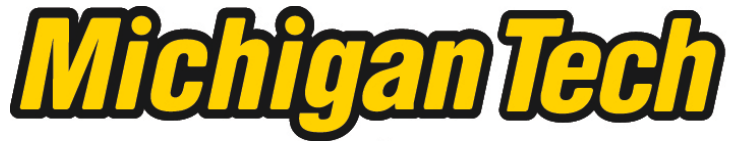 \\ Michigan Technological University Create the Future Digital Commons @ Michigan Tech
}

Dissertations, Master's Theses and Master's Reports - Open

Dissertations, Master's Theses and Master's

Reports

2012

Optimization of redundancy in branched water distribution systems

Megan L. Abbott

Michigan Technological University

Follow this and additional works at: https://digitalcommons.mtu.edu/etds

Part of the Civil and Environmental Engineering Commons

Copyright 2012 Megan L. Abbott

\section{Recommended Citation}

Abbott, Megan L., "Optimization of redundancy in branched water distribution systems ", Master's report, Michigan Technological University, 2012.

https://doi.org/10.37099/mtu.dc.etds/512

Follow this and additional works at: https://digitalcommons.mtu.edu/etds

3 Part of the Civil and Environmental Engineering Commons 


\title{
OPTIMIZATION OF REDUNDANCY IN BRANCHED WATER DISTRIBUTION SYSTEMS
}

\author{
By \\ Megan L. Abbott \\ A REPORT \\ Submitted in partial fulfillment of the requirements for the degree of \\ Master of Science in Environmental Engineering \\ MICHIGAN TECHNOLOGICAL UNIVERSITY \\ 2012 \\ (C) 2012 Megan Abbott
}


This report, "Optimization of Redundancy in Branched Water Distribution Systems," is hereby approved in partial fulfillment of the requirements for the Degree of MASTER OF SCIENCE IN ENVIRONMENTAL ENGINEERING.

Department of Civil and Environmental Engineering

Signatures:

Report Advisor

Brian Barkdoll

Department Chair

David Hand

Date 


\section{Table of Contents}

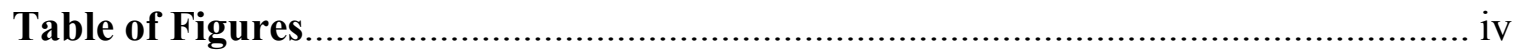

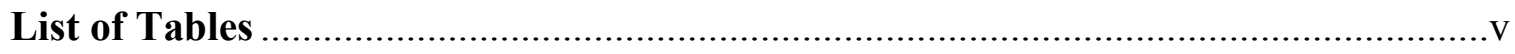

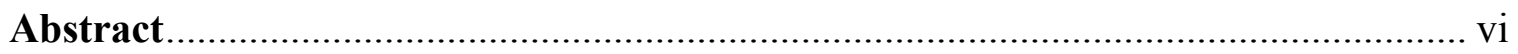

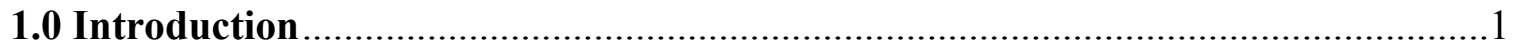

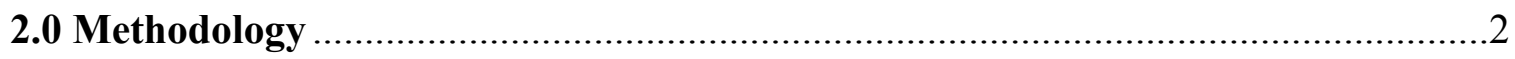

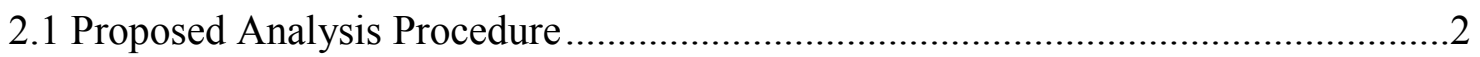

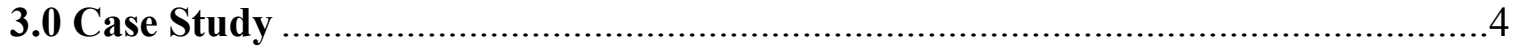

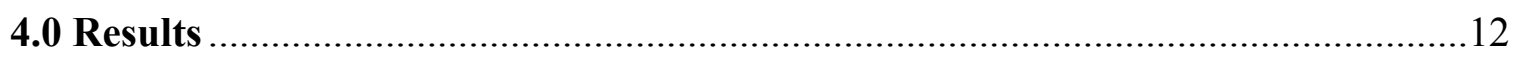

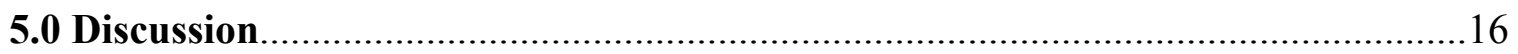

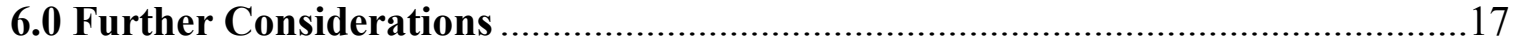

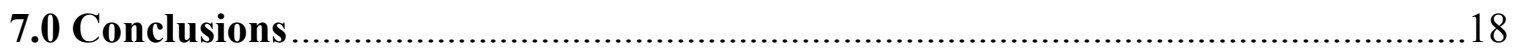

8.0 Recommendations ........................................................................................ 18

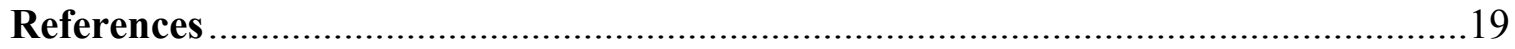

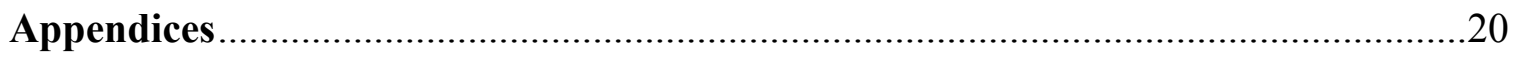

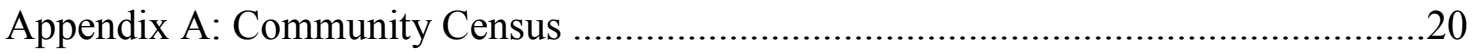

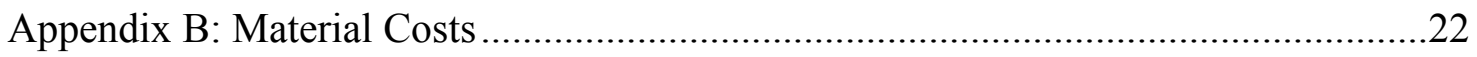

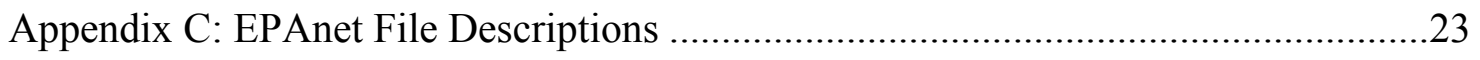




\section{Table of Figures}

Figure 1. Map of Belize with location of the case study area indicated. Source: MapsOf.net ........ 4

Figure 2. Contour plot of the Medina Bank water distribution system ......................................... 5

Figure 3. Water system source during the dry season. The solar pump is submersed in the spring.

Figure 4. Water system source overrun by the Deep River. .................................................... 6

Figure 5. The Deep River during flooding towards the end of the rainy season. The river is a few

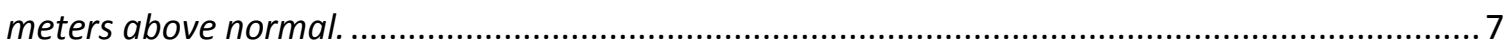

Figure 6. Typical water tap. The spigots are wrapped in cloth to strain out any sediment, and to reduce spraying.

Figure 7. Typical water access point. Sheds are used to enclose the taps.................................. 8

Figure 8. Demand in liters per minute (Ipm) at 06:00 (peak demand time) ................................ 10

Figure 9. Possible loops for the Medina Bank water system. Loop 12 is installed prior to using the proposed procedure (since it provides redundancy to the entire system) to determine the benefits of the remaining loops. 11

Figure 10. Locations of preschools considered (triangle symbols denote simulated locations of vulnerable users such as schools). 


\section{List of Tables}

Table 1. Quantity of water collected by service level (adapted from Howard and Bartram 2003) 9

Table 2. Base demand multipliers for the Medina Bank water system

(actual demand = demand multiplier $\mathrm{x}$ average demand described above in Figure 8)

Table 3. Cost of loops in Medina Bank water distribution system with Loop 12 connected ........13

Table 4. Total number of users benefited per USD from installation of a loop (TUB criteria)..... 14

Table 5. Number of vulnerable users benefiting per USD from installation of a loop (VUB criteria)

Table 6. Ranking of loops for each preschool scenario in terms of number of vulnerable users benefited per USD (VUB criteria).

Table 7. Ranking of loops for different weighting of vulnerable users to non-vulnerable users benefiting with a preschool on Loop 1 


\begin{abstract}
In developing countries many water distribution systems are branched networks with little redundancy. If any component in the distribution system fails, many users are left relying on secondary water sources. These sources oftentimes do not provide potable water and prolonged use leads to increased cases of water borne illnesses. Increasing redundancy in branched networks increases the reliability of the networks, but is oftentimes viewed as unaffordable. This paper presents a procedure for water system managers to use to determine which loops when added to a branch network provide the most benefit for users. Two methods are presented, one ranking the loops based on total number of users benefited, and one ranking the loops of number of vulnerable users benefited. A case study is presented using the water distribution system of Medina Bank Village, Belize. It was found that forming loops in upstream pipes connected to the main line had the potential to benefit the most users.
\end{abstract}




\subsection{Introduction}

Many factors affect the design of a water distribution system: environmental, financial, and legal to name a few. In areas where the limiting factor is financial, the number of resources used in a design would be limited in order to limit the system cost. Developing countries, or other communities limited by financial resources, may design their system using the minimum amount of materials needed to meet the demands of the system. As stated in both Mihelcic et al. (2009) and Jordan (2006), developing countries use mainly branched water distribution systems. This means that each demand node is served by only one pathway, thus reducing the budget by excluding extra piping costs. As stated by Cembrowicz (1992), "In case of economic planning or urgent remedy, a branched network may suffice". Branched networks are sufficient for meeting demands provided there are no breaks, leaks or damage to any part of the system. In the case of damage to the system, nodes downstream of the damage would be without service. Providing a secondary pathway would be ideal, but may not be financially feasible for every demand node.

In communities where finances are not the limiting factor, water distribution systems are much more robust. Yazdani and Jeffrey (2012) defined robustness as "the optimal connectivity of a network to reduce the probability of hydraulic failures or to reduce the consequences of component failures". The way this is done is through increasing reliability. The reduction in consequences is achieved through the addition of loops to the system. Loops provide redundancy and increased reliability. Redundancy is provided by the addition of alternative paths between the source and demand nodes that can be used to satisfy supply requirements during failure of the main paths (Goulter 1987). Increased paths between demand nodes and sources increase the probability that a system will be operational, and that demand is met which are two of the definitions for reliability presented by Baranowski et al. (2003). It can be seen then that providing redundancy increases the reliability of a water distribution system. Therefore, in terms of reliability, an ideal water system would be one with high amounts of redundancy.

Water systems with limited or no redundancy are more likely to have outages due to leaks, breakages, or other component failures. In developing communities, these outages require users to seek water from secondary sources; oftentimes these sources are surface water, springs or wells (WHO 2011). If a secondary source is unprotected, the water may not be potable and may increase the number of cases of water related illnesses in the community. Side effects of water borne illnesses such as diarrhea can have significant impacts upon life and productivity for those affected, and is the second leading cause of death for children under five years old (WHO 2009). For the purpose of this report, 
"vulnerable users" refers to children under five years old. Increasing the reliability of the water distribution system, therefore, could have a positive effect on vulnerable users.

Providing redundancy for every demand node in a branched system may not be possible at one time for communities with limited funding. It may be necessary to add in loops as funding becomes available. This paper presents a procedure for determining which loops would be the most beneficial to a system in terms of number of users benefited and cost.

The procedure presented in this paper is applied to the water system in Medina Bank village in Belize. The author served in Medina Bank as a community health/water and sanitation volunteer through the United States Peace Corps from 2009 to 2011. During this time she worked on women's health projects, a nutrition program in the school, established a library, and worked with the Village Council and Water Board on various projects. The water distribution system has been operating effectively since 2009, and the Water Board has been able to save the majority of the fees collected from the users over these years. After the Water Board purchases a backup pump, the fees collected can then be put towards making extensions and improvements while keeping a reserve for unanticipated repairs. The proposed procedure was used to examine the benefits of improving redundancy in the Medina Bank water distribution systems in order to provide recommendations to the Water Board as to where they should make investments.

\subsection{Methodology}

Since children are more vulnerable to bacterial diseases brought about by the introduction of contaminated water due to a pipe break, this report examines two different methods for analyzing the benefits of providing redundancy through the installation of loops into a branched water distribution system. The first method considers the total number of users benefited from the installation of the loop (Total-Users-Benefited or TUB), while the second method considers the number of vulnerable users benefited (Vulnerable-UsersBenefitted or VUB). The following procedure is the same for both methods except where noted in Step 3 (shown below) when determining the number of users benefited.

EPAnet was used to model the systems examined in this paper. EPAnet is a program developed by the United States Environmental Protection Agency to model water distribution systems (EPA 2012). The program can model the hydraulic behavior of a water distribution system over a period of time.

\subsection{Proposed Analysis Procedure:}

The following general procedure allows system managers to decide which loops are the most beneficial if funding is not sufficient to connect all loops at once. 


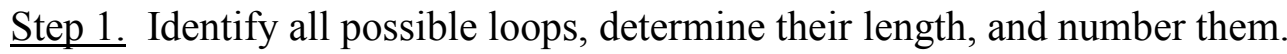

Step 2: Determining pipe diameters:

a. Using EPAnet, connect only the first loop and choose a reasonable diameter for the new pipe.

b. Close one of the pipes on the loop (to simulate a break)*, and run the simulation. Check the pressures throughout the system to make sure they satisfy pressure requirements at each node by being greater than $3 \mathrm{~m}$ of head at all system junctions. If not, increase the diameter of the newly-added pipe (and adjoining pipes if necessary) until pressure is above $3 \mathrm{~m}$ of head everywhere.

c. Repeat Step $2 \mathrm{~b}$ for each of the pipes in the loop in turn. Record the diameter and the length of pipe needed.

Step 3. Determining the number of users benefited:

Simulate a break in the water main line on the loop by closing this pipe (the pipe supplying water to the rest of the system downstream of the loop in question). Identify the number of users that benefit from the installation of the loop according to one of the following methods. Keep in mind users benefited can be located outside of the loop, e.g. users located downstream of the new loop.

a. For Total Users Benefited: Count all users receiving water via the new loop.

b. For Vulnerable Users: Count number of vulnerable users (children age 5 and under) receiving water via the new loop. If applicable, choose a time of day when vulnerable users are present at preschools, schools, daycares, etc. and account for them in those places.

Step 4. Remove the loop and return the system to its original state. Make sure all diameters have been returned to the original sizes and reopen any closed pipes.

Step 5. Repeat Steps 2 and 3 for each of the loops in the system.

Step 6. Determine the cost of materials for connecting each individual loop, including the larger diameter pipes required to meet system pressure requirements, if any.

Step 7. Divide the number of users benefited for each loop determined in Step 3 by the cost for that loop.

Step 8. In order to determine the second most beneficial loop, connect the loop from Step 7 using EPAnet. Then repeat Steps 1-7 with this loop connected. Continue to repeat this process, each time installing one more loop, in order to rank all of the loops from most beneficial to least beneficial. Complete loops in the ranked order as funds permit. 
*It is important to note that simulating a break by closing the pipe assumes that shutoff valves will close off the portion of pipe with the break. This ensures that the loop being tested would be able to meet demands if the break was not immediately repaired.

\subsection{Case Study}

Medina Bank is a Q'eqchi Maya village located in the southernmost district of Belize. It is located at the foothills of the Maya Mountains, and bordered to the north by the Deep River. The village has 261 residents, a primary school, community center, churches and a guest house that is currently not in operation (census data is in Appendix A). The village water distribution system serves the majority of these residents and buildings.

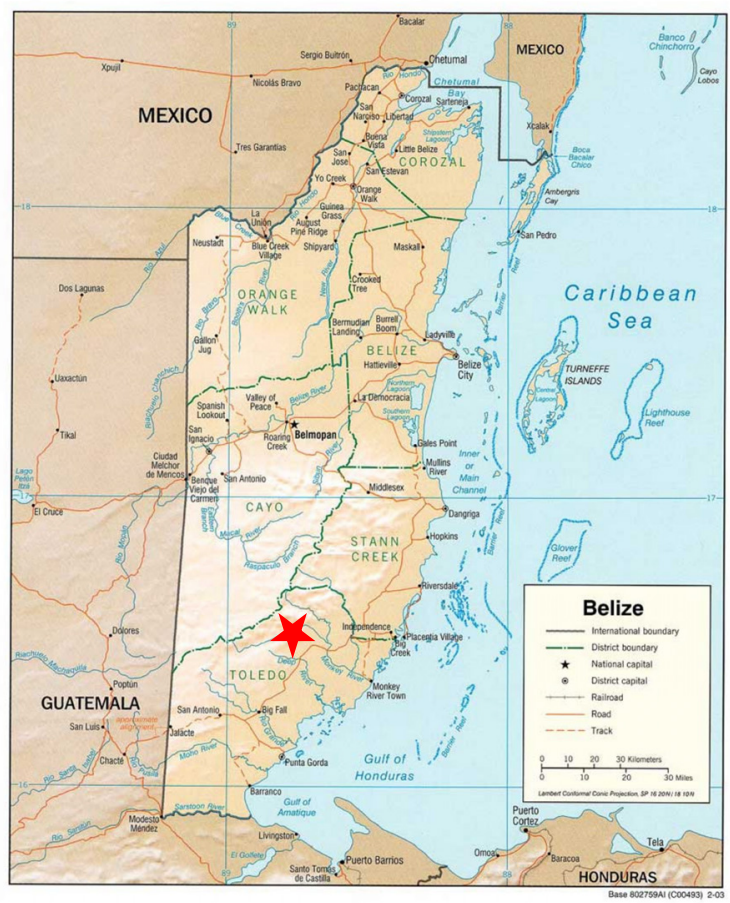

Figure 1. Map of Belize with location of the case study area indicated.

Source: MapsOf.net

The source for the water distribution system is a spring bordering the Deep River. The spring is easily accessed during the dry season, however as it begins to rain the river overtakes the cove where the spring is located potentially causing some contamination of the source. For this system the primary source may not be potable, but in many cases the primary source for a community is potable. 
A water pump is submersed inside the spring and is powered by four 180-watt solar panels. The pump sends water to two 10,000 L tanks that feed the distribution system. The solar panels and pump were installed by a local non-government organization to replace a broken pump that was powered by a diesel generator. The majority of households in the village are served by the distribution system; however, extensions need to be made to some households. The houses without taps in their lot usually access water from a family member or neighbor's tap. The users do pay a minimal monthly fee to the village water board to help with maintenance and repair costs. In cases of outages for the system, most people use the hand pumps as a secondary source, although, some who live close to the river retrieve water from the river or spring. These wells likely contribute to the number of water-borne illnesses within the village population as the water is not potable. There is no information on the depth or construction of the wells; however, there are concerns about the proximity to latrines and the general quality of the water.

The distribution system itself spans approximately one-half kilometer from source to the end of the water main and is constructed from PVC. The system serves 41 households, 3 churches, the primary school and a community center. There are no commercial or livestock demands on the system. All water used for livestock purposes comes from the hand pump wells. As can be seen in Figure 2, the distribution goes predominately downhill from the storage tanks, except for one small hill in the middle of the distribution system.

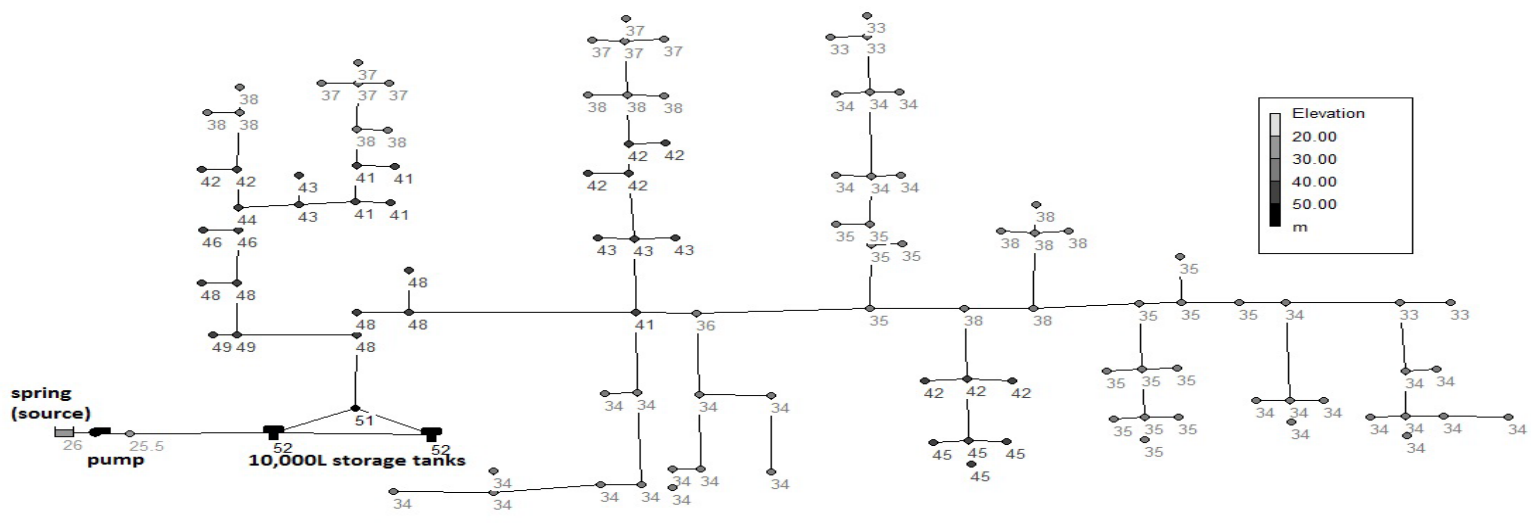

Figure 2. Contour plot of the Medina Bank water distribution system 
The following photos illustrate the case study area, river, and parts of the water distribution system.

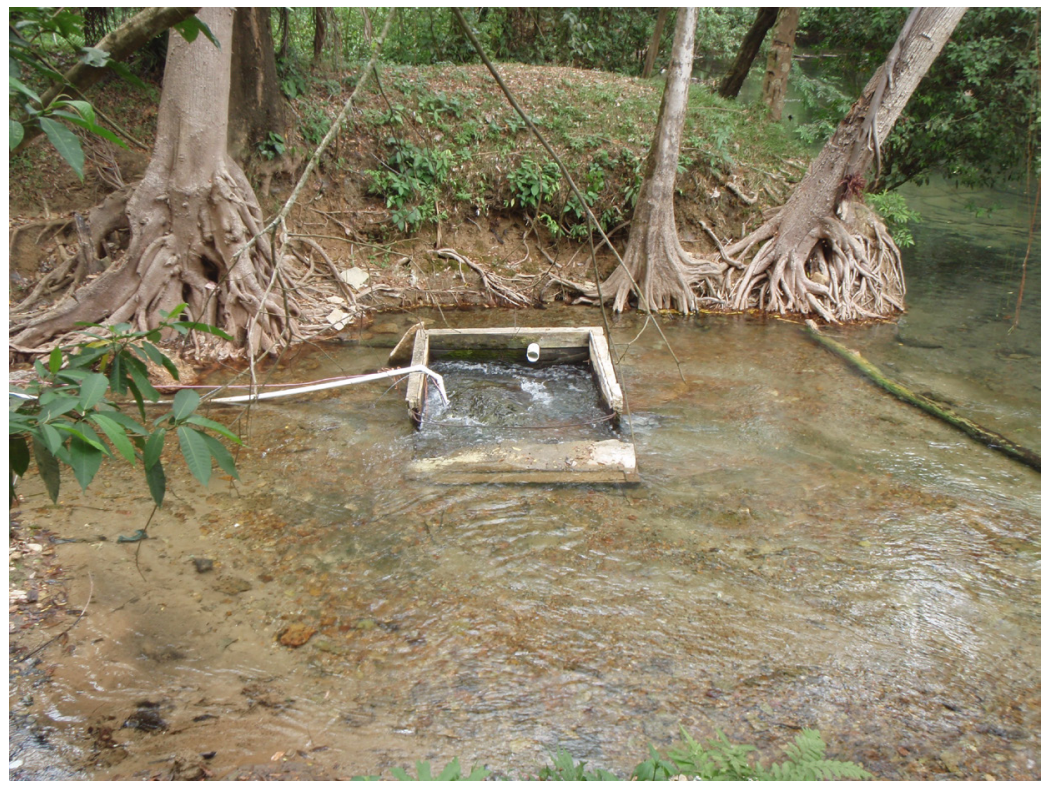

Figure 3. Water system source during the dry season. The solar pump is submersed in the spring.

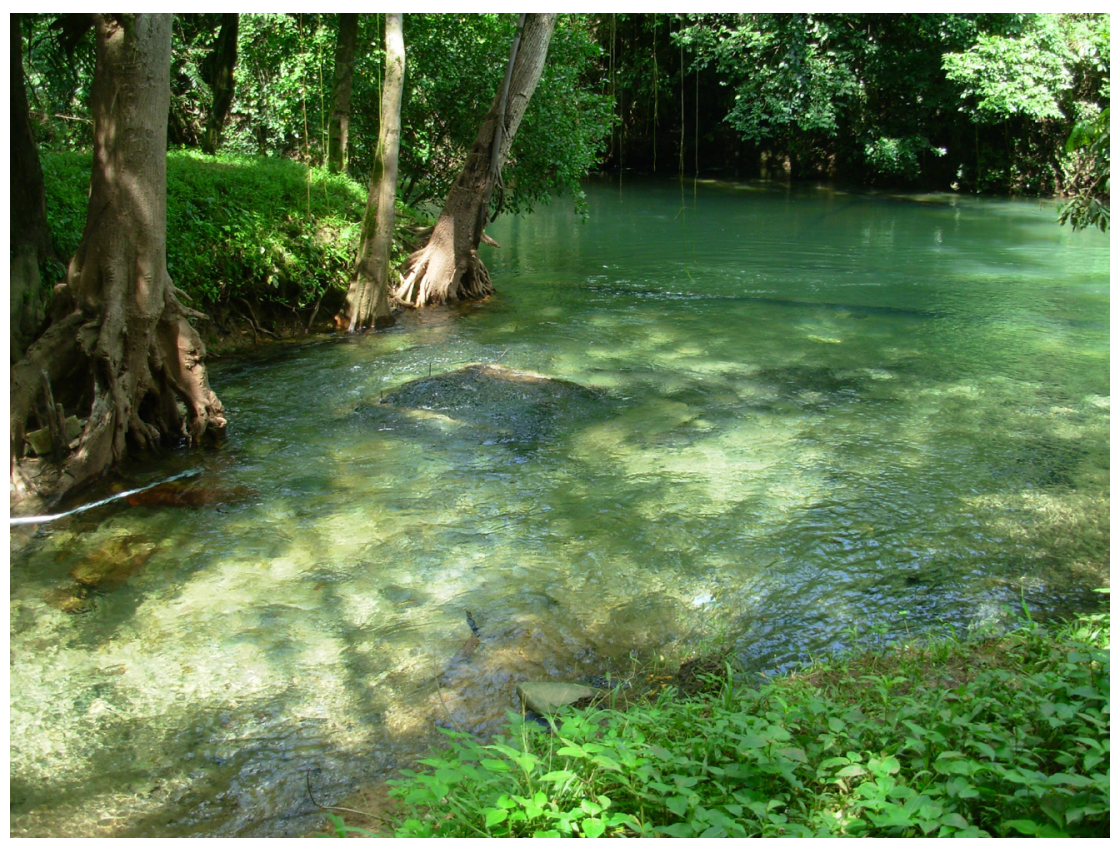

Figure 4. Water system source overrun by the Deep River. 


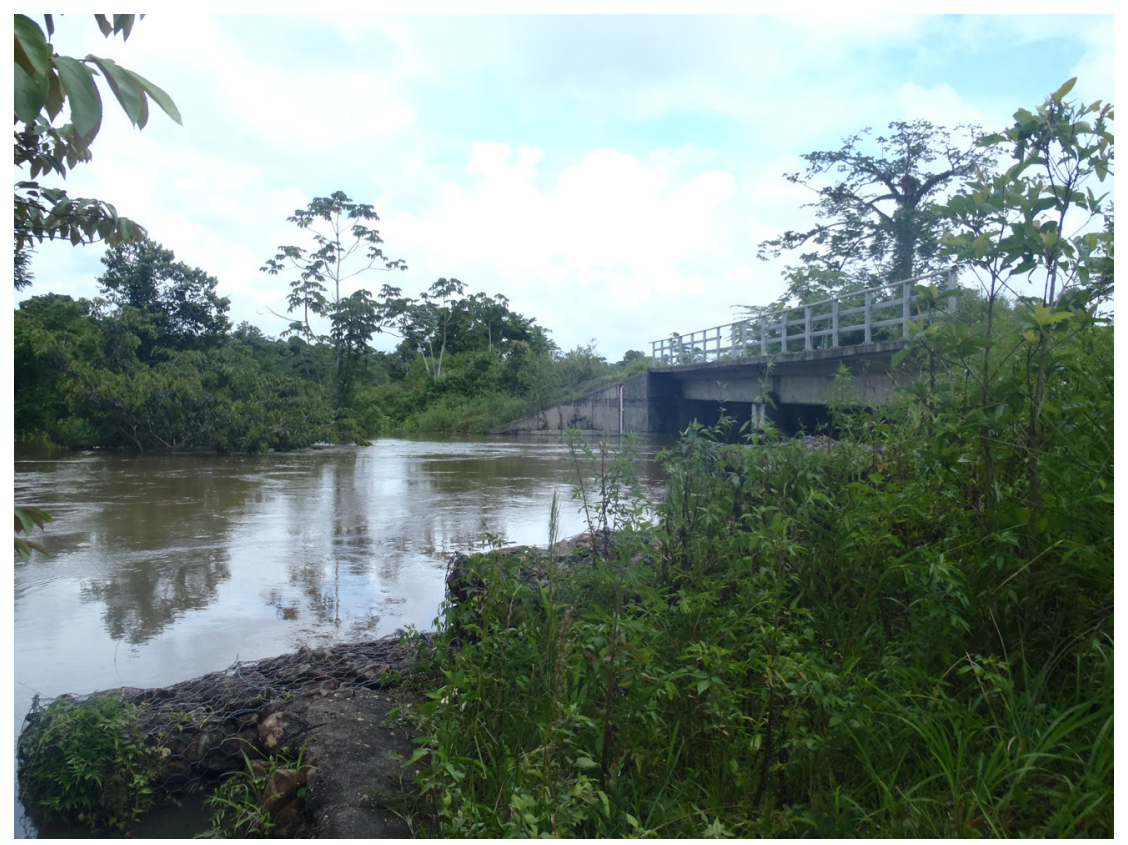

Figure 5. The Deep River during flooding towards the end of the rainy season. The river is a few meters above normal.

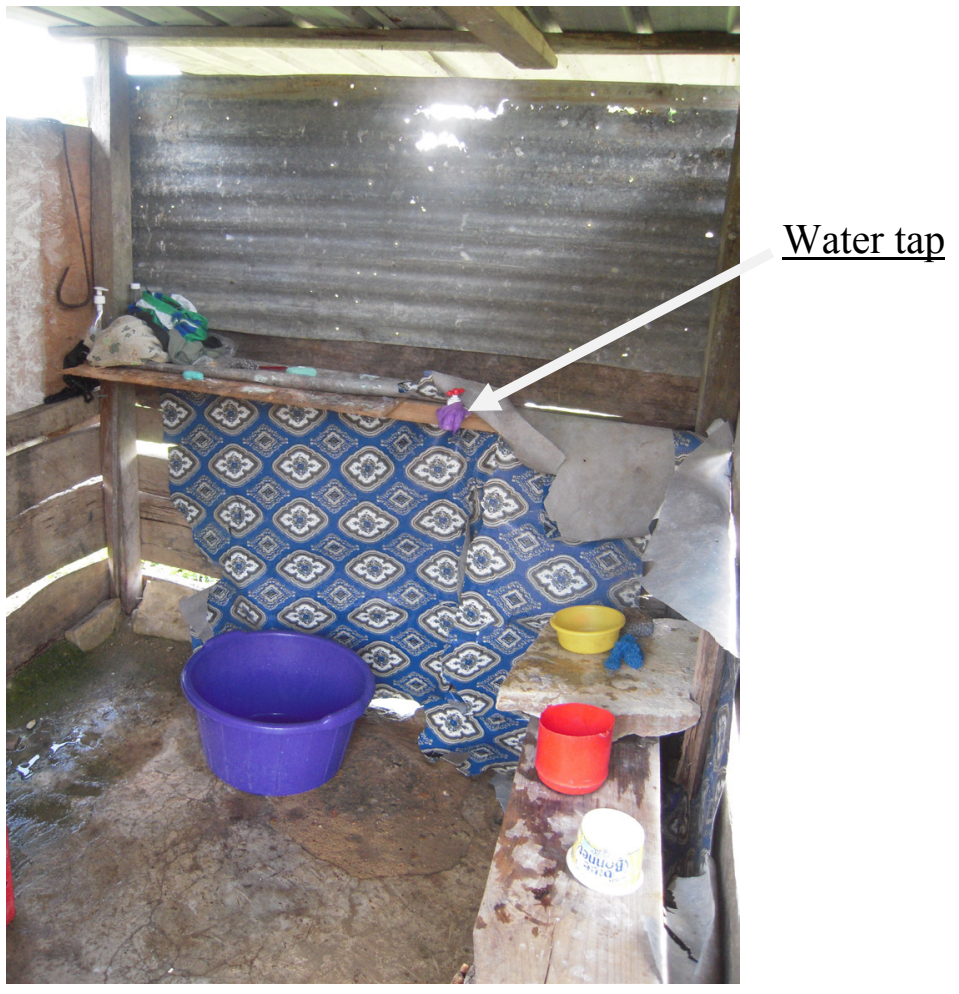

Figure 6. Typical water tap. The spigots are wrapped in cloth to strain out any sediment, and to reduce spraying. 


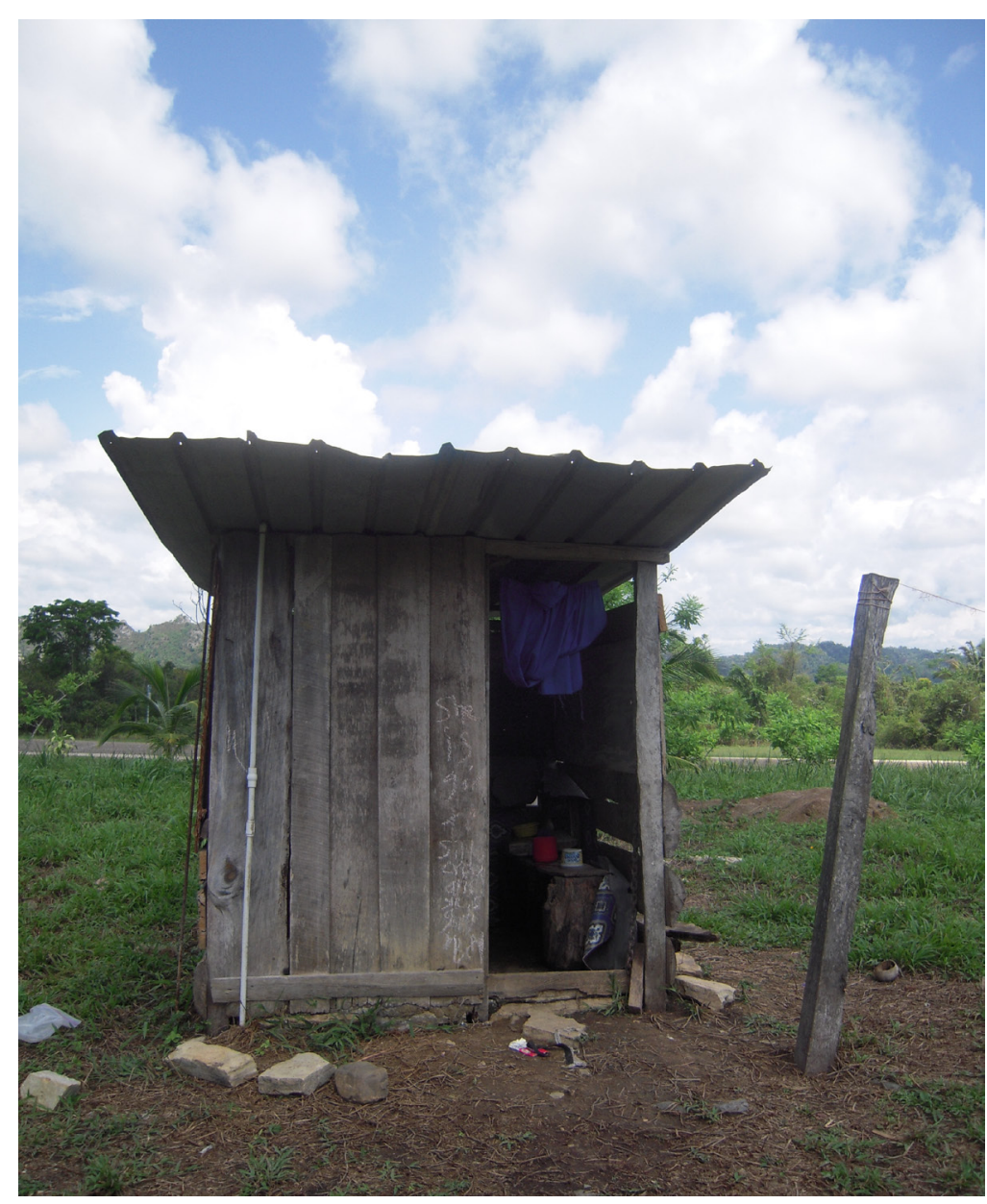

Figure 7. Typical water access point. Sheds are used to enclose the taps.

The Medina Bank Village water distribution system was used to examine the proposed procedure. This system is ideal for evaluating the procedure as it is a small branched system, with only 12 potential loops. The system was modeled on EPAnet using the information gathered from the community survey (See Appendix A) completed by the author along with village leaders and elders.

After the basic distribution system was input into EPAnet, demands were determined based on observation and existing literature. According to the World Health Organization, daily recommendations for per-capita water usage depend upon the proximity of the access point to the home as can be seen in Table 1 (Howard and Bartram 2003). 
Table 1. Quantity of water collected by service level (adapted from Howard and Bartram 2003)

\begin{tabular}{|c|c|c|c|}
\hline Service Level & Access measure & Needs met & Level of health concern \\
\hline No access (quantity & More than $1000 \mathrm{~m}$ or & Consumption -- cannot be assured & Very high \\
\hline collected often & 30 minutes total & Hygiene -- not possible (unless & \\
\hline below $5 \mathrm{l} / \mathrm{c} / \mathrm{d}$ ) & collection time & practised at source) & \\
\hline Basic access & Between 100 and & Consumption -- should be assured & High \\
\hline (average quantity & $1000 \mathrm{~m}$ or 5 to 30 & Hygiene -- handwashing and basic food & \\
\hline unlikely to exceed & minutes total & hygiene possible; laundry/bathing & \\
\hline \multirow[t]{2}{*}{$20 \mathrm{l} / \mathrm{c} / \mathrm{d})$} & collection time & difficult to assure unless carried & \\
\hline & & out at source & \\
\hline Intermediate access & Water delivered & Consumption -- assured & Low \\
\hline (Average quantity & through one tap on- & Hygiene -- all basic personal and food & \\
\hline \multirow[t]{3}{*}{ about 50 l/c/d) } & plot (or within 100m & hygiene assured; laundry and bathing & \\
\hline & or 5 minutes total & should also be assured & \\
\hline & collection time & & \\
\hline Optimal access & Water supplied & Consumption -- all needs met & Very low \\
\hline (average quantity & through multiple taps & Hygiene -- all needs should be met & \\
\hline $100 \mathrm{l} / \mathrm{c} / \mathrm{d}$ and & continuously & & \\
\hline above) & & & \\
\hline
\end{tabular}

The majority of users have intermediate access as there is a tap present on their lot. However, many of the more recent homes have not been included in the current system, and users must walk to neighboring homes to retrieve water. These users would fall in the 'basic access' category. Another consideration in determining the daily demand per capita is the limitations of the system during the rainy season. During this time cloud cover limits the operating hours of a solar system without battery backup and, therefore, not as much water is available for use. Therefore many of the households use their water only for cooking and drinking; bathing, and laundering take place at the river.

Considering this limitation, observations of water usage by the author, and the WHO guidelines, the total demand was assumed to be 20 liters per day per capita per day $(\mathrm{L} / \mathrm{c} / \mathrm{d})$. During the course of modeling it was determined the system is capable of providing a maximum of $45 \mathrm{~L} / \mathrm{c} / \mathrm{d}$. The average demand for each junction was calculated by multiplying the number of users at that junction by $20 \mathrm{~L} / \mathrm{c} / \mathrm{d}$. For an average household the demand is $120 \mathrm{~L} / \mathrm{d}$ or 0.084 liters per minute. The average demands for the nodes are shown in Figure 8. 


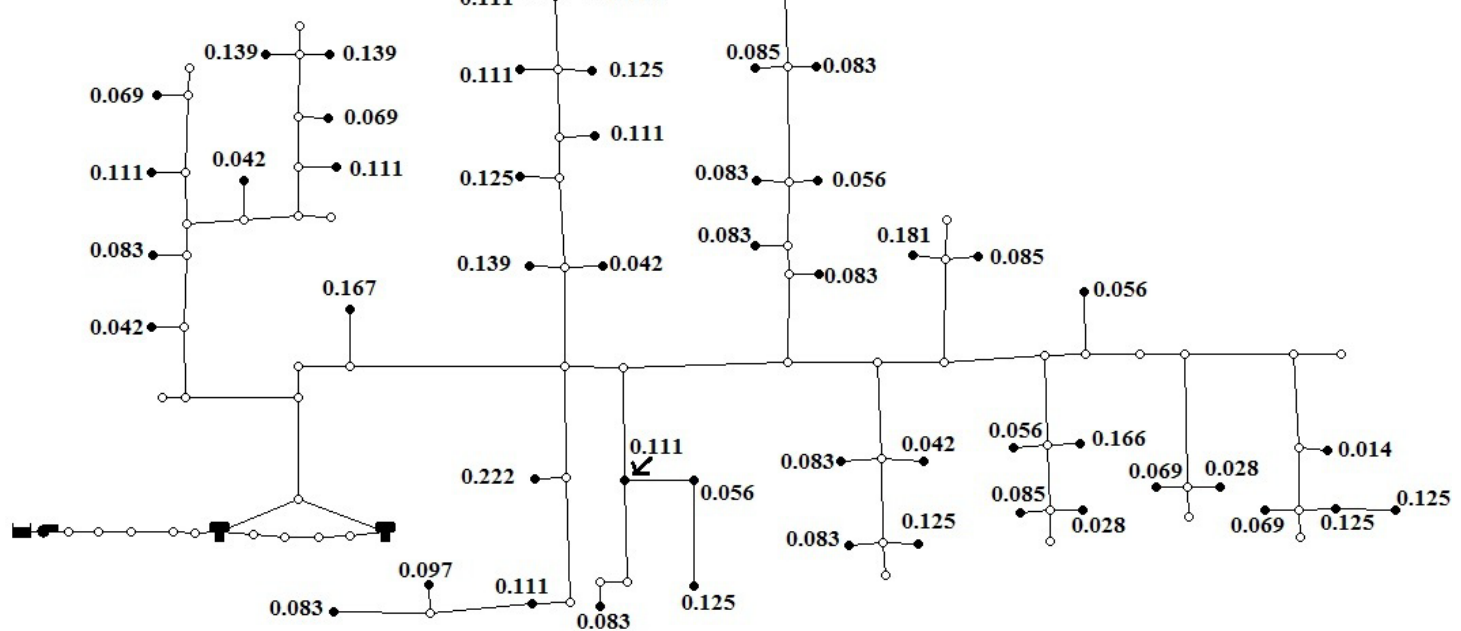

Figure 8. Demand in liters per minute (lpm) at 06:00 (peak demand time)

The demand is not constant throughout the day, so demand patterns were created to be used in the non-steady state (Extended-Period Simulation) analysis of the system. The pattern shown in Table 2 was created based on the author's observations. It was observed that much of the water for daily use was gathered in the morning hours and stored in buckets. Other small increases in demand can be seen around meal times, when more people are present in the home. The demand pattern was made for a 48-hour period including both a Sunday, when churches and the community center are used, and a weekday, when school is in session. The demand multipliers from Table 2 were multiplied by the average demands (above) to determine the actual demand for each node at any given time.

A demand pattern was also necessary to simulate daylight hours for pump operation. The pump is powered by solar panels without battery backup, therefore during nondaylight hours it is shutoff. The daylight hours are fairly consistent throughout the year, so the pump was set to run from 6:00-18:00 every day. 
Table 2. Base demand multipliers for the Medina Bank water system (actual demand $=$ demand multiplier $x$ average demand described above in Figure 8)

\begin{tabular}{|c|c|c|c|c|}
\hline Time & Household & School & Church & Community Center \\
\hline \multicolumn{5}{|c|}{ Sunday } \\
\hline $0: 00-6: 00$ & 0 & 0 & 0 & 0 \\
\hline $6: 00-8: 00$ & 3 & 0 & 6 & 0 \\
\hline $8: 00-10: 00$ & 1 & 0 & 6 & 0 \\
\hline $10: 00-12: 00$ & 2 & 0 & 0 & 0 \\
\hline $12: 00-14: 00$ & 1 & 0 & 0 & 6 \\
\hline 14:00-16:00 & 2 & 0 & 0 & 6 \\
\hline $16: 00-18: 00$ & 3 & 0 & 0 & 0 \\
\hline $18: 00-20: 00$ & 1 & 0 & 0 & 0 \\
\hline $20: 00-24: 00$ & 0 & 0 & 0 & 0 \\
\hline \multicolumn{5}{|c|}{ Weekday } \\
\hline $0: 00-6: 00$ & 0 & 0 & 0 & 0 \\
\hline $6: 00-8: 00$ & 3 & 3 & 0 & 0 \\
\hline $8: 00-10: 00$ & 1 & 3 & 0 & 0 \\
\hline $10: 00-12: 00$ & 2 & 3 & 0 & 0 \\
\hline $12: 00-14: 00$ & 1 & 3 & 0 & 0 \\
\hline 14:00-16:00 & 2 & 0 & 0 & 0 \\
\hline 16:00-18:00 & 3 & 0 & 0 & 0 \\
\hline $18: 00-20: 00$ & 1 & 0 & 0 & 0 \\
\hline $20: 00-24: 00$ & 0 & 0 & 0 & 0 \\
\hline
\end{tabular}

After completing the model of the system in EPAnet, the system was analyzed using the proposed procedure described above. The Medina Bank water system has 12 possible loops as can be seen in Figure 1.

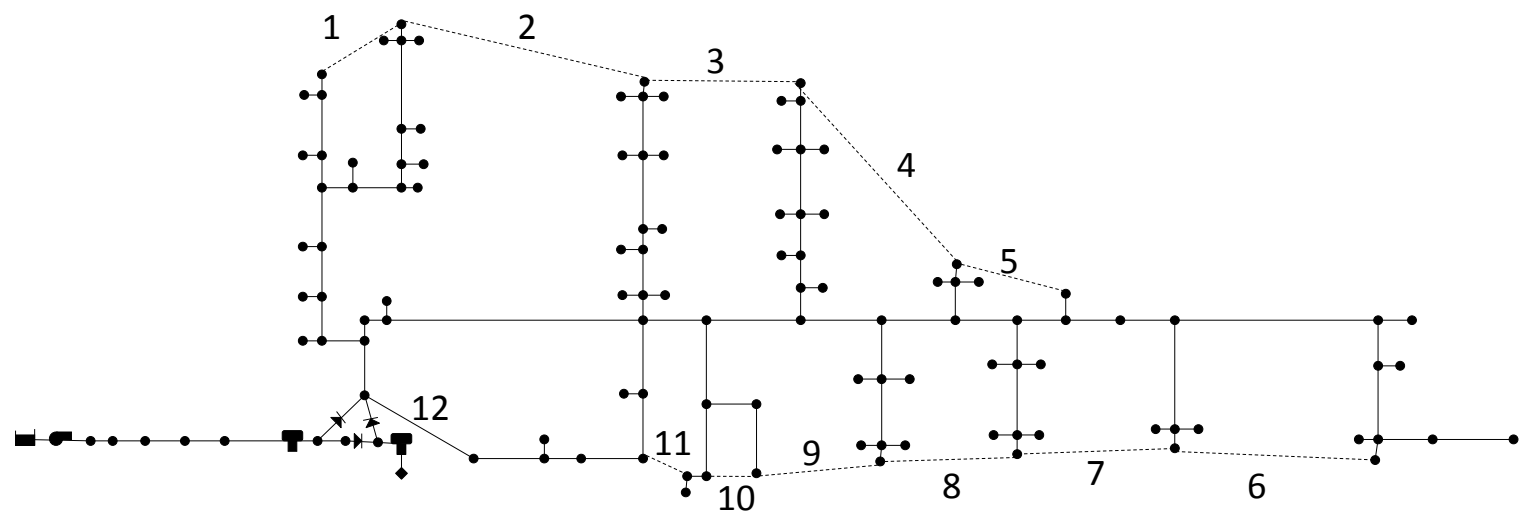

Figure 9. Possible loops for the Medina Bank water system. Loop 12 is installed prior to using the proposed procedure (since it provides redundancy to the entire system) to determine the benefits of the remaining loops. 
When looking at the system, there is only a single pipe that connects the source to the rest of the system and, therefore, does not guarantee supply to the rest of the system since a pipe break in this single line denies water to all the rest of the system. In order to provide redundancy for the supply pipe, Loop 12 was connected prior to evaluating the benefits of the other loops with the proposed procedure. With this loop installed, the remaining loops were compared using the proposed procedure. The most beneficial loop was found, installed and the remaining loops compared using the same procedure to find the next most beneficial loop. This was repeated until every loop was ranked. Both the TUB and the VUB criteria were used to evaluate the benefits of Loops 1 through 11 .

This system does not have a pre-school, orphanage, or place where vulnerable users would congregate. In order to determine if such a place would change the ranking of the loops, three different locations for a preschool were considered. As can be seen in Figure 10 , one location was upstream, one was in the middle of the system, and one at the downstream end away from the source. For the analysis done with a preschool, all children preschool age (3-5 years old) were considered to be present at the preschool instead of at home.

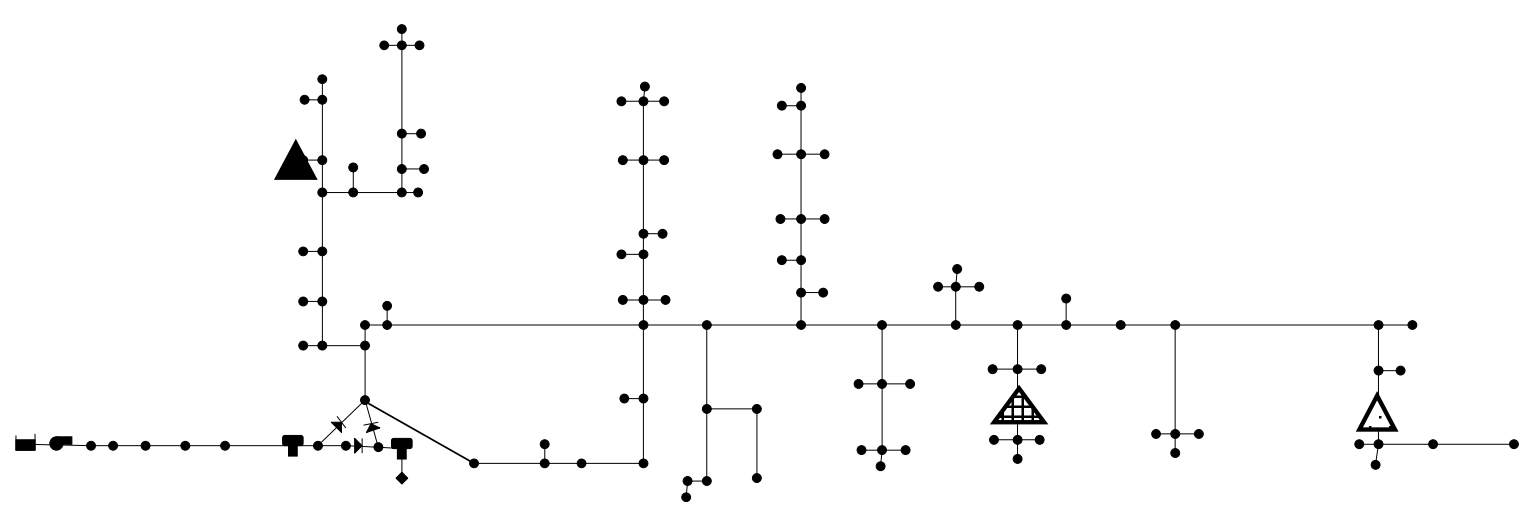

Figure 10. Locations of preschools considered (triangle symbols denote simulated locations of vulnerable users such as schools).

\subsection{Results}

Both user criteria (TUB and VUB) provided similar results, with most of them favoring the installation of upstream Loop 11; however, an exception was found when the Vulnerable User Method (VUB) was used. Tables 3-7 give more details of the results from each scenario.

Table 3 shows the length of each loop, diameter, the total length to be replaced, and the cost for each of the eleven loops (1-11). The loop length and length to be replaced differ 
in loops where sufficient pressure or demand was not able to be met with increasing the diameter of the new pipe alone. In these cases current piping upstream or downstream were replaced with pipe of greater diameter in order to increase pressure and meet demands. Loop 3 was the most expensive even though the new pipe length was not very long because it required increasing the diameter of pipes upstream. Whereas the new pipe for Loop 11 covers a short distance and can be accomplished without changing any of the current pipes and is, therefore, less expensive.

Table 3. Cost of loops in Medina Bank water distribution system with Loop 12 connected

\begin{tabular}{|r|r|r|r|r|}
\hline Loop Number & $\begin{array}{c}\text { New Pipe } \\
\text { Length } \mathbf{( m )}\end{array}$ & $\begin{array}{c}\text { Total Pipe Length to be } \\
\text { Added or Replaced }(\mathbf{m})\end{array}$ & $\begin{array}{c}\text { Pipe Diameter, } \\
\text { inches (mm) }\end{array}$ & Cost (USD) \\
\hline 1 & 54.3 & 54.3 & $0.5(12.7)$ & $\$ 61.88$ \\
\hline 2 & 101.7 & 101.7 & $1(25.4)$ & $\$ 142.38$ \\
\hline 3 & 75.2 & 157.1 & $1(25.4)$ & $\$ 217.75$ \\
\hline 4 & 132.1 & 132.1 & $0.75(19.05)$ & $\$ 162.25$ \\
\hline 5 & 58.7 & 58.7 & $0.5(12.7)$ & $\$ 68.75$ \\
\hline 6 & 93.0 & 93.0 & $0.5(12.7)$ & $\$ 110.00$ \\
\hline 7 & 68.0 & 68.0 & $0.5(12.7)$ & $\$ 82.50$ \\
\hline 8 & 79.8 & 79.8 & $0.5(12.7)$ & $\$ 96.25$ \\
\hline 9 & 58.0 & 129.1 & $0.75(19.05)$ & $\$ 162.25$ \\
\hline 10 & 42.5 & 42.5 & $0.5(12.7)$ & $\$ 48.13$ \\
\hline 11 & 27.2 & 27.2 & $1(25.4)$ & $\$ 41.88$ \\
\hline
\end{tabular}

From Table 4 of the final loop ranking it can be seen that Loop 11 provided the most users with redundancy per cost. Connecting Loop 11 requires a short pipe but is towards the upstream end of the system and, therefore, has a fairly large number of users downstream. This loop benefits 3.03 users/USD, where the other loops all have values less than 2 users/USD (see Appendix B for cost data). For all pipes, costs include only material costs as labor is provided by village members for any community project. It can be seen that some of the costs for loops are lower in Table 4 than in Table 3. For example, Loop 9 was the $2^{\text {nd }}$ most beneficial loop and cost $\$ 73.75$ according to Table 4 . This cost is lower than the cost of Loop 9 listed in Table 3 because increasing the diameter of pipes upstream of the loop was no longer necessary once Loop 11 was installed. For Loops 10 and 4 all users that could potentially be benefited by the addition of the loop already have been provided with a $2^{\text {nd }}$ pathway; therefore, no new users benefit from the installation of either loop. 
Table 4. Total number of users benefited per USD from installation of a loop (TUB criteria).

\begin{tabular}{|r|r|r|r|r|}
\hline Rank & Loop Number & Users Benefiting & Cost (USD) & Users/USD \\
\hline \hline 1 & 11 & 127 & $\$ 41.88$ & 3.03 \\
\hline 2 & 9 & 100 & $\$ 73.75$ & 1.36 \\
\hline 3 & 1 & 58 & $\$ 61.88$ & 0.94 \\
\hline 4 & 5 & 50 & $\$ 68.75$ & 0.73 \\
\hline 5 & 8 & 63 & $\$ 96.25$ & 0.65 \\
\hline 6 & 3 & 47 & $\$ 89.38$ & 0.53 \\
\hline 7 & 2 & 58 & $\$ 125.38$ & 0.46 \\
\hline 8 & 7 & 31 & $\$ 82.50$ & 0.38 \\
\hline 9 & 6 & 24 & $\$ 110.00$ & 0.22 \\
\hline 10 & 10 & 0 & $\$ 48.35$ & 0.00 \\
\hline 11 & 4 & 0 & $\$ 151.25$ & 0.00 \\
\hline
\end{tabular}

When the Vulnerable User Method, VUB, was used to rank the benefits of the loops, the results were the same as for the TUB. Table 5 shows the most beneficial loop is again Loop 11. The similarity of the results from the two methods seems to imply that in a system with no points of congregation for vulnerable users (preschools, orphanages, etc.) the distribution of vulnerable users will be similar to the distribution of total users. The even distribution of vulnerable users among the population is confirmed by the census data. In this case, when considering vulnerable users, the ranking of loops would be nearly the same when considering only vulnerable users benefited, to using the VUB method and considering vulnerable users/cost.

Table 5. Number of vulnerable users benefiting per USD from installation of a loop (VUB criteria)

\begin{tabular}{|r|r|r|r|r|}
\hline Rank & Loop Number & Vulnerable Users Benefiting & Cost (USD) & Vulnerable Users/USD \\
\hline \hline 1 & 11 & 27 & $\$ 41.88$ & 0.64 \\
\hline 2 & 9 & 23 & $\$ 73.75$ & 0.31 \\
\hline 3 & 1 & 14 & $\$ 61.88$ & 0.23 \\
\hline 4 & 5 & 11 & $\$ 68.75$ & 0.16 \\
\hline 5 & 8 & 12 & $\$ 96.25$ & 0.12 \\
\hline 6 & 3 & 11 & $\$ 89.38$ & 0.12 \\
\hline 7 & 2 & 14 & $\$ 125.38$ & 0.11 \\
\hline 8 & 7 & 7 & $\$ 82.50$ & 0.08 \\
\hline 9 & 6 & 4 & $\$ 110.00$ & 0.04 \\
\hline 10 & 10 & 0 & $\$ 48.13$ & 0.00 \\
\hline 11 & 4 & 0 & $\$ 151.25$ & 0.00 \\
\hline
\end{tabular}


Table 6 shows the ranking of loops for the scenarios including preschools on Loops 1, 8 and 6 (Figure 10). It can be seen that for each scenario, the loop on which the preschool was located increased in ranking from when no preschool was present. For the preschool on Loop 1 (furthest upstream), the most beneficial loop changed to Loop 1. However, for the two downstream preschool scenarios the respective loops were higher in the rankings, but Loop 11 was still the most beneficial. This is because Loop 1 is in the upstream portion of the system. If a preschool is located upstream of the most beneficial loop not considering vulnerable users (in this case Loop 11), it will become the most beneficial loop when considering vulnerable users. If the preschool is located downstream, both loops would benefit equally and the most beneficial loop would stay the same (such as in the Loop 8 and Loop 6 scenarios).

Table 6. Ranking of loops for each preschool scenario in terms of number of vulnerable users benefited per USD (VUB criteria)

\begin{tabular}{|c|c|c|c|c|}
\hline Rank & No Preschool & Preschool on Loop 1 & Preschool on Loop 8 & Preschool on Loop 6 \\
\hline \hline 1 & 11 & 1 & 11 & 11 \\
\hline 2 & 9 & 11 & 8 & 5 \\
\hline 3 & 1 & 2 & 9 & 7 \\
\hline 4 & 5 & 9 & 1 & 8 \\
\hline 5 & 8 & 5 & 2 & 9 \\
\hline 6 & 3 & 8 & 5 & 1 \\
\hline 7 & 2 & 4 & 7 & 2 \\
\hline 8 & 7 & 7 & 4 & 4 \\
\hline 9 & 6 & 6 & 6 & 3 \\
\hline 10 & 10 & 10 & 10 & 10 \\
\hline 11 & 4 & 3 & 3 & \\
\hline
\end{tabular}

The scenario with a preschool present on Loop 1 was examined more closely to determine how much weighting must be put on the vulnerable users in order for Loop 1 to be more beneficial than Loop 11. Equation 1 was used to calculate the number of users benefited per USD.

$$
\frac{U \text { sers }}{U S D}=\frac{w_{v}(\text { vulnerable users })+w_{n}(\text { non }- \text { vulnerable users })}{\text { cost }}
$$

where $\mathrm{w}_{\mathrm{v}}$ is the weighting for vulnerable users and $\mathrm{w}_{\mathrm{n}}$ is the weighting for non-vulnerable users.

The results seen in Table 7 show that only vulnerable users can be considered in order for Loop 1 to be the most important. At a weighting of 90/10 (vulnerable to non-vulnerable) the two loops were equal in importance. The rankings for all weightings except $100 \%$ 
vulnerable users were nearly identical. The only difference was in 50/50 where the $3^{\text {rd }}$ and $4^{\text {th }}$ ranking loops switched places.

If the main concern for providing redundancy is to benefit vulnerable users, and minimize sickness in children, then weighting $100 \%$ vulnerable users is appropriate. However, if lost working hours due to adult sickness is a concern, then all users should be considered in increasing redundancy and a weighting factor of greater than 0 should be given to non-vulnerable users.

Table 7. Ranking of loops for different weighting of vulnerable users to nonvulnerable users benefiting with a preschool on Loop 1

\begin{tabular}{|c|c|c|c|c|c|c|}
\hline Rank & $\mathbf{5 0 \% / 5 0 \%}$ & $\mathbf{6 0 \% / 4 0 \%}$ & $\mathbf{7 0 \% / 3 0 \%}$ & $\mathbf{8 0 \% / 2 0 \%}$ & $\mathbf{9 0 \% / 1 0 \%}$ & $\mathbf{1 0 0 \%}$ \\
\hline \hline 1 & 11 & 11 & 11 & 11 & 11 & 1 \\
\hline 2 & 1 & 1 & 1 & 1 & 1 & 11 \\
\hline 3 & 5 & 2 & 2 & 2 & 2 & 2 \\
\hline 4 & 2 & 5 & 5 & 5 & 5 & 9 \\
\hline 5 & 8 & 8 & 8 & 8 & 8 & 5 \\
\hline 6 & 9 & 9 & 9 & 9 & 9 & 8 \\
\hline 7 & 4 & 4 & 4 & 4 & 4 & 4 \\
\hline 8 & 7 & 7 & 7 & 7 & 7 & 7 \\
\hline 9 & 6 & 6 & 6 & 6 & 6 & 6 \\
\hline 10 & 10 & 10 & 10 & 10 & 10 & 10 \\
\hline 11 & 3 & 3 & 3 & 3 & 3 & 3 \\
\hline
\end{tabular}

\subsection{Discussion}

For this case study, the first-ranking loop was determined outside of the proposed procedure. In the case of a single supply pipe from the source, it is important to connect a loop first that provides redundancy from the source to the distribution system.

Otherwise, a failure in the supply pipe would cut off all demand nodes from the source.

The proposed procedure was used to rank each of the remaining loops using both TUB and VUB methods. The results for the two methods produced identical results when using the case study water distribution system. For this reason, it can be assumed that in systems where there is no daycare, preschool, etc., the vulnerable user population is distributed equally among the users. Once a preschool was included in the system, though, there were differences between the TUB and VUB results. The Loop 6 and Loop 8 preschool scenarios still produced results ranking Loop 11 as the most beneficial loop. It can be seen from Figure 9 that both Loops 6 and 8 are downstream from Loop 11. 
Adding a preschool to either Loop 8 or Loop 6 increases the number of vulnerable users the loops benefits respectively. However, since these loops are located downstream of Loop 11, it also increases the number of users benefited by Loop 11. This is not true in a situation such as the Loop 1 preschool scenario, where the loop containing the preschool is furthest upstream.

It is important to keep the motivation for installing loops in mind when making the decision as to which loop is priority. If the motivation of the decision making group is to benefit the most users for the amount of money they have to spend, the ranking obtained by the procedure presented in this paper is adequate. However, if the motivation is to ensure water for a vulnerable population, other considerations may be necessary. If there is a preschool or other congregation of vulnerable users in the community, then the loop containing the preschool may be first priority even if it is not the highest ranking loop, especially in situations where the preschool is located on a downstream loop where it could suffer outages from a break in any of the different pipes upstream.

\subsection{Further Considerations}

If the main sources of pipe breakages in a distribution system are preventable through other methods (e.g. burying pipes deeper, teaching proper installation techniques) then increasing redundancy should be compared with these methods to determine which is the better option.

There are some effects of increasing redundancy in a water distribution system, other than increased reliability, that should be considered when deciding if and where redundancy should be increased. If redundancy is increased and all users are able to receive water even when a break occurs, then breaks may not be identified as easily. A user reporting an outage is one of the most common ways for a break to be discovered. Other methods include visible spraying of water from a pipe, pooling of water above ground, and decreased pressure downstream. Once the break is identified, it is important that it be repaired in a reasonable amount of time, even if all users are still receiving water. If repairs are put off until outages occur, then no benefit comes from increasing redundancy. If a break is not repaired, then the redundancy is negated, so it is important for repairs to occur in a timely manner.

The methods for ranking addition of loops to a system discussed in this paper, TUB and VUB methods, consider only benefits to users, and the cost of the improvements when ranking the loops. In order to use the TUB method, all users must be considered equally important. Ideally this would be true; however, in some cases leaders, elders, or others 
may value themselves more than others, and thus place a greater importance on loops that benefit themselves. Similarly, the VUB method requires everyone to view the vulnerable population as most important.

\subsection{Conclusions}

Water distribution systems are designed to provide users with adequate quantities of water to meet their daily demand needs. However, the reliability of water distribution systems varies greatly between different communities. Branched networks, as are often used in developing communities, have little or no redundancy. These systems tend to be unreliable and result in increased cases of water borne diseases due to the amount of time users must rely on secondary sources. Increasing redundancy and thus improving the reliability of distribution networks would lower the number of days users must rely on secondary sources, and therefore the number of cases of water borne disease.

This paper has addressed the prioritization of loops for installation in situations where finances are not adequate to install all loops at one time. By ranking the loops according to the total number of users benefited, or the vulnerable users benefited, decision making groups can prioritize the installation of loops in their distribution and provide redundancy over time, as funds become available. These methods showed that upstream loops connected to the main line have the potential to benefit the most users. Therefore the upstream loops with the lowest cost should be connected first, then middle, and then downstream loops last. When considering vulnerable users, upstream loops with the greatest congregation of vulnerable users should be first priority. .

\subsection{Recommendations}

For the Medina Bank water distribution system, redundancy should be provided first for the supply pipe, via the installation of Loop 12. After this, if money is available the village Water Board can consider the addition of loops in the order found in Table 4. The Water Board should examine the existing distribution system to ensure all pipes are buried to avoid accidental damage. They should also ensure that for future extensions all pipes are buried at adequate depth and joined using proper technique to minimize the probability of failure. 


\section{References}

. "Belize Topological Map." Retrieved March, 2012, from mapsof.net/belize.

Baranowski, T. M., T. M. Walski, Z. Y. Wu, R. Mankowski, W. Hartell (2003). Trading Off Reliability and Cost in Optimal Water Distribution System Design, ASCE.

Cembrowicz, R. G. (1992). Water Supply Systems Optimization for Developing Countries. International Conference on Pipeline Systems. Manchester, UK: 59-76.

Goulter, I. C. (1987). "Current and Future Use of Systems Analysis in Water Distribution Network Design." Civil Engineering Systems 4(4): 175-184.

Howard, G. and J. Bartram (2003). Domestic Water Quantity, Service, Level and Health. Geneva, Switzerland, World Health Organization (WHO).

Jordan Jr., T. D. (2006). A Handbook of Gravity-Flow Water Systems for Small Communities. London, Intermediate Technology Publications.

Mihelcic, J. R., L. M. Fry, E. A. Myre, L. D. Phillips, B. D. Barkdoll (2009). Field Guide to Environmental Engineering for Development Workers. Reston, VA, American Society of Civil Engineers, 2009.

United States Environmental Protection Agency (2012). "EPAnet." Retrieved March, 2012, from http://www.epa.gov/nrmrl/wswrd/dw/epanet.html.

World Health Organization (2009). "Diarrhoeal Disease Fact Sheet." 2012, from http://www.who.int/mediacentre/factsheets/fs330/en/index.html.

World Health Organization (2011). "Global Health Observatory Data Repository." 2012, from http://apps.who.int/ghodata/.

Yazdani, A. and P. Jeffrey (2012). "Applying Network Theory to Quantify the Redundancy and Structural Robustness of Water Distribution Systems." Journal of Water Resources Planning and Management 138(2): 153-161. 


\section{Appendices}

\section{Appendix A: Community Census}

Community census information was collected by the author through the work with the Water Board and a community health survey conducted with the village Health Worker.

\begin{tabular}{|c|c|c|c|c|c|c|c|}
\hline \multirow[b]{2}{*}{ Household } & \multirow{2}{*}{$\begin{array}{l}\text { Node } \\
\text { ID }\end{array}$} & \multirow{2}{*}{$\begin{array}{l}\text { Adult } \\
\text { Males }\end{array}$} & \multirow{2}{*}{$\begin{array}{l}\text { Adult } \\
\text { Females }\end{array}$} & \multicolumn{2}{|c|}{ Children (Age) } & \multirow{2}{*}{$\begin{array}{c}\text { Total } \\
\text { Population }\end{array}$} & \multirow{2}{*}{$\begin{array}{c}\text { Water Access } \\
\text { Point }\end{array}$} \\
\hline & & & & $0-5$ & $6+$ & & \\
\hline 1 & 2 & 1 & 1 & 4 & 0 & 6 & Pipe @ home \\
\hline 2 & 21 & 1 & 1 & 0 & 4 & 6 & Pipe @ home \\
\hline 3 & 43 & 1 & 0 & 0 & 0 & 1 & Pipe @ home \\
\hline 4 & 1 & 1 & 1 & 1 & 0 & 3 & Pipe @ home \\
\hline 5 & 3 & 1 & 1 & 1 & 5 & 8 & Pipe @ home \\
\hline 6 & 4 & 1 & 2 & 2 & 0 & 5 & Pipe @ home \\
\hline 7 & 5 & 2 & 1 & 0 & 0 & 3 & Pipe@ @ome \\
\hline 8 & 6 & 2 & 2 & 1 & 5 & 10 & Pipe @ home \\
\hline 9 & 7 & 1 & 1 & 2 & 7 & 11 & Pipe @ home \\
\hline 10 & 8 & 1 & 1 & 3 & 0 & 5 & Pipe @ home \\
\hline 11 & 9 & 1 & 1 & 0 & 6 & 8 & Pipe @ home \\
\hline 12 & 12 & 2 & 2 & 1 & 3 & 8 & Pipe @ home \\
\hline 13 & 13 & 1 & 1 & 2 & 5 & 9 & Pipe @ home \\
\hline 14 & 14 & 1 & 1 & 2 & 6 & 10 & Pipe@ @ome \\
\hline 15 & 19 & 2 & 6 & 7 & 1 & 16 & hand pump \\
\hline 16 & 16 & 1 & 1 & 3 & 4 & 9 & Pipe@ @ome \\
\hline 17 & 17 & 1 & 1 & 2 & 4 & 8 & hand pump \\
\hline 18 & 18 & 1 & 1 & 1 & 0 & 3 & Pipe @ home \\
\hline 19 & 23 & 1 & 1 & 0 & 6 & 8 & Pipe @ home \\
\hline 20 & 25 & 1 & 1 & 1 & 6 & 9 & hand pump \\
\hline 21 & 29 & 1 & 1 & 1 & 7 & 10 & Pipe @ home \\
\hline 22 & 27 & 1 & 1 & 3 & 1 & 6 & Pipe @ home \\
\hline 23 & 24 & 1 & 1 & 2 & 0 & 4 & Pipe@ @ome \\
\hline 24 & 30 & 1 & 1 & 3 & 2 & 7 & Pipe @ home \\
\hline 25 & 31 & 1 & 1 & 2 & 0 & 4 & Pipe @ home \\
\hline 26 & 32 & 1 & 1 & 1 & 3 & 6 & Pipe @ home \\
\hline 27 & 33 & 1 & 1 & 0 & 4 & 6 & Pipe @ home \\
\hline 28 & 35 & 1 & 1 & 1 & 0 & 3 & Pipe @ home \\
\hline 29 & 37 & 1 & 0 & 0 & 0 & 1 & Pipe @ neighbor \\
\hline 30 & 37 & 3 & 3 & 1 & 5 & 12 & Pipe @ home \\
\hline 31 & 39 & 1 & 1 & 2 & 0 & 4 & Pipe @ home \\
\hline 32 & 41 & 1 & 1 & 2 & 2 & 6 & Pipe @ home \\
\hline 33 & 41 & 1 & 2 & 0 & 4 & 7 & pipe @ neighbor \\
\hline
\end{tabular}




\begin{tabular}{|c|c|c|c|c|c|c|c|}
\hline & Node & Adult & Adult & \multicolumn{2}{|c|}{ Children (Age) } & Total & Water Access \\
\cline { 5 - 8 } Household & ID & Males & Females & $0-5$ & $6+$ & Population & Point \\
\hline 34 & 42 & 1 & 1 & 0 & 0 & 2 & Pipe @ home \\
\hline 35 & 26 & 1 & 1 & 1 & 3 & 6 & Pipe @ neighbor \\
\hline 36 & 44 & 1 & 1 & 3 & 0 & 5 & Pipe @ home \\
\hline 37 & 45 & 0 & 2 & 0 & 0 & 2 & Pipe @ home \\
\hline 38 & 46 & 0 & 1 & 0 & 0 & 1 & Pipe @ home \\
\hline 39 & 47 & 1 & 1 & 2 & 1 & 5 & Pipe @ home \\
\hline 40 & 48 & 1 & 1 & 1 & 6 & 9 & Pipe @ home \\
\hline 41 & 49 & 1 & 1 & 1 & 6 & 9 & Pipe @ neighbor \\
\hline Primary School & 10 & -- & -- & -- & -- & -- & pipe on lot \\
\hline $\begin{array}{c}\text { Community } \\
\text { Center }\end{array}$ & 20 & -- & -- & -- & -- & -- & pipe on lot \\
\hline Guest House & 36 & -- & -- & -- & -- & -- & pipe on lot \\
\hline $\begin{array}{c}\text { Catholic } \\
\text { Church }\end{array}$ & 26 & -- & -- & -- & -- & -- & pipe on lot \\
\hline Baptist Church & 34 & -- & -- & -- & -- & -- & pipe on lot \\
\hline $\begin{array}{c}\text { Pentecostal } \\
\text { Church }\end{array}$ & 49 & -- & -- & -- & -- & -- & pipe on lot \\
\hline \begin{tabular}{c} 
Total \\
\hline
\end{tabular} & & 45 & 51 & 59 & 106 & 261 & \\
\hline
\end{tabular}

$*_{\text {for node ID refer to image below }}$

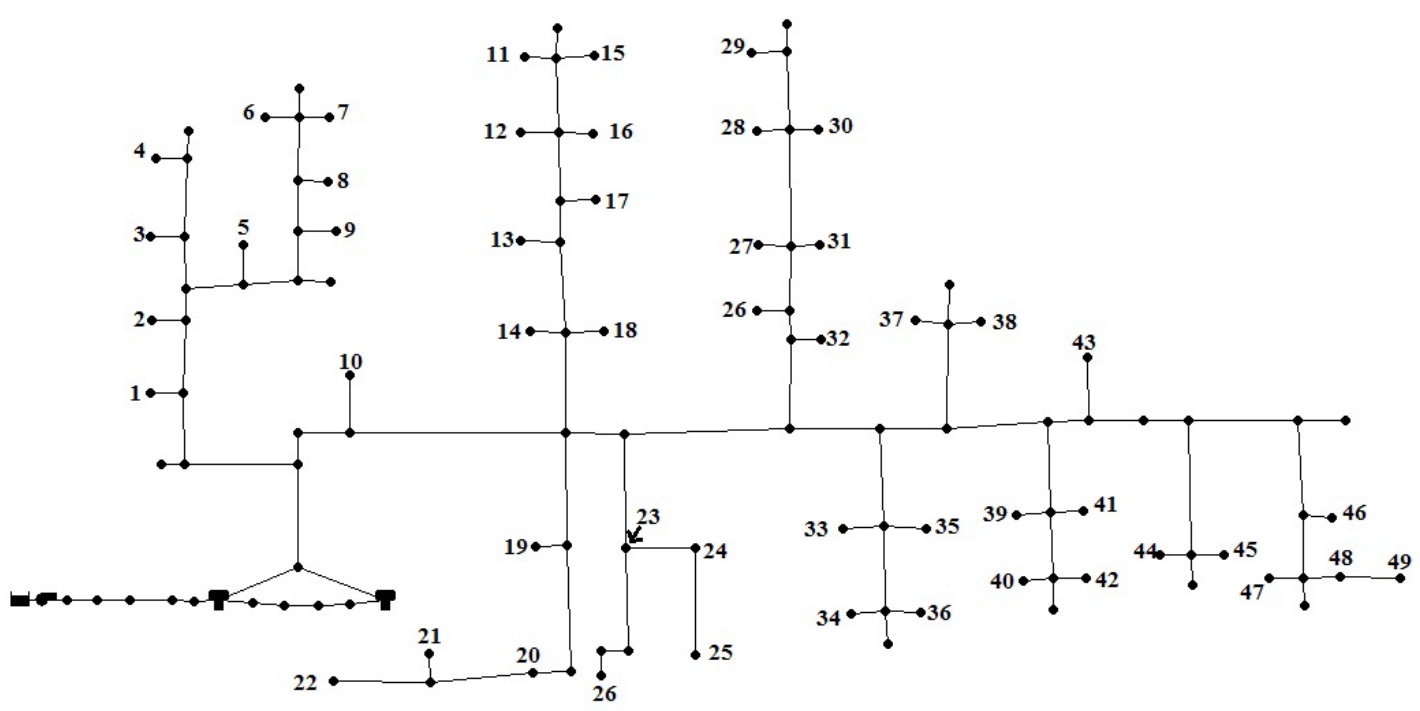




\section{Appendix B: Material Costs}

The prices listed are the actual purchase price from hardware stores in the district town. Labor costs were not included in any calculations as it is provided by the village for any community project.

\begin{tabular}{|l|l|l|}
\hline Pipe Diameter (inches) & Cost/20ft length (BZD) & Cost/20ft length (USD) \\
\hline 0.5 & $\$ 13.75$ & $\$ 6.88$ \\
\hline 0.75 & $\$ 14.75$ & $\$ 7.38$ \\
\hline 1 & $\$ 16.75$ & $\$ 8.38$ \\
\hline 1.5 & $\$ 17.75$ & $\$ 8.88$ \\
\hline
\end{tabular}




\section{Appendix C: EPAnet File Descriptions}

These files can be found on the attached data CD.

1. Grundfos 11 SQF 2 Pump Curve and Information

2. EPAnet Steady-state scenario: EPAnet file modeling Medina Bank system using base demand, no demand or pump patterns.

3. Steady-state output summary: Summary of the Medina Bank system using base demand, no demand or pump patterns. Includes input pipe diameter and lengths, and output demands, head and pressure.

4. EPAnet Unsteady-state scenario: Medina Bank system modeled as-is, using demand and pump patterns over 48 hours.

5. Unsteady-state scenario output summary: Summary of the Medina Bank system modeled as-is over 48 hours. Includes input pipe diameter and lengths, and output demands, head and pressure.

6. EPAnet Unsteady-state scenario including Loop 12: Medina Bank system modeled including Loop 12 as redundancy to the tanks. 48-hour simulation.

7. Unsteady-state scenario including Loop 12 output summary: Medina Bank system modeled including Loop 12 as redundancy to the tanks. 48-hour simulation. Includes input pipe diameter and lengths, and output demands, head and pressure.

Files 8-29 are for the analysis of which Loop to install after installing Loop 12 . Used to determine which loop ranked \#1:

8. EPAnet loop analysis - Loop 12 plus Loop 1

9. Output summary: loop analysis - Loop 12 plus Loop 1

10. EPAnet loop analysis - Loop 12 plus Loop 2

11. Output summary: loop analysis - Loop 12 plus Loop 2

12. EPAnet loop analysis - Loop 12 plus Loop 3

13. Output summary: loop analysis - Loop 12 plus Loop 3

14. EPAnet loop analysis - Loop 12 plus Loop 4

15. Output summary: loop analysis - Loop 12 plus Loop 4 
16. EPAnet loop analysis - Loop 12 plus Loop 5

17. Output summary: loop analysis - Loop 12 plus Loop 5

18. EPAnet loop analysis - Loop 12 plus Loop 6

19. Output summary: loop analysis - Loop 12 plus Loop 6

20. EPAnet loop analysis - Loop 12 plus Loop 7

21. Output summary: loop analysis - Loop 12 plus Loop 7

22. EPAnet loop analysis - Loop 12 plus Loop 8

23. Output summary: loop analysis - Loop 12 plus Loop 8

24. EPAnet loop analysis - Loop 12 plus Loop 9

25. Output summary: loop analysis - Loop 12 plus Loop 9

26. EPAnet loop analysis - Loop 12 plus Loop 10

27. Output summary: loop analysis - Loop 12 plus Loop 10

28. EPAnet loop analysis - Loop 12 plus Loop 11

29. Output summary: loop analysis - Loop 12 plus Loop 11

Files 30-49 are for the analysis after installing Loops 12 and 11 . Used to determine which loop ranked \#2:

30. EPAnet loop analysis - Loops 12, 11 plus Loop 1

31. Output summary: loop analysis - Loops 12,11 plus Loop 1

32. EPAnet loop analysis - Loops 12, 11 plus Loop 2

33. Output summary: loop analysis - Loops 12 , 11 plus Loop 2

34. EPAnet loop analysis - Loops 12, 11 plus Loop 3

35. Output summary: loop analysis - Loops 12 , 11 plus Loop 3

36. EPAnet loop analysis - Loops 12, 11 plus Loop 4

37. Output summary: loop analysis - Loops 12,11 plus Loop 4 
38. EPAnet loop analysis - Loops 12, 11 plus Loop 5

39. Output summary: loop analysis - Loops 12,11 plus Loop 5

40. EPAnet loop analysis - Loops 12, 11 plus Loop 6

41. Output summary: loop analysis - Loops 12,11 plus Loop 6

42. EPAnet loop analysis - Loops 12, 11 plus Loop 7

43. Output summary: loop analysis - Loops 12,11 plus Loop 7

44. EPAnet loop analysis - Loops 12, 11 plus Loop 8

45. Output summary: loop analysis - Loops 12,11 plus Loop 8

46. EPAnet loop analysis - Loops 12, 11 plus Loop 9

47. Output summary: loop analysis - Loops 12, 11 plus Loop 9

48. EPAnet loop analysis - Loops 12,11 plus Loop 10

49. Output summary: loop analysis - Loops 12,11 plus Loop 10

Files 50-67 are for the analysis after installing Loops 12, 11, and 9. Used to determine which loop ranked \#3:

50. EPAnet loop analysis - Loops 12, 11, 9 plus Loop 1

51. Output summary: loop analysis- Loops 12,11 , 9, plus Loop 1

52. EPAnet loop analysis - Loops 12, 11, 9 plus Loop 2

53. Output summary: loop analysis- Loops $12,11,9$, plus Loop 2

54. EPAnet loop analysis - Loops 12, 11, 9 plus Loop 3

55. Output summary: loop analysis- Loops 12,11 , 9, plus Loop 3

56. EPAnet loop analysis - Loops 12, 11, 9 plus Loop 4

57. Output summary: loop analysis- Loops 12,11 , 9, plus Loop 4

58. EPAnet loop analysis - Loops 12, 11, 9 plus Loop 5

59. Output summary: loop analysis- Loops $12,11,9$, plus Loop 5 
60. EPAnet loop analysis - Loops 12, 11, 9 plus Loop 6

61. Output summary: loop analysis- Loops $12,11,9$, plus Loop 6

62. EPAnet loop analysis - Loops 12, 11, 9 plus Loop 7

63. Output summary: loop analysis- Loops $12,11,9$, plus Loop 7

64. EPAnet loop analysis - Loops 12, 11, 9 plus Loop 8

65. Output summary: loop analysis- Loops 12,11 , 9, plus Loop 8

66. EPAnet loop analysis - Loops 12, 11, 9 plus Loop 10

67. Output summary: loop analysis- Loops 12,11 , 9, plus Loop 10

Files 68-83 are for the analysis after installing Loops $12,11,9$, and 1 . Used to determine which loop ranked \#4:

68. EPAnet loop analysis - Loops 12, 11, 9, 1 plus Loop 2

69. Output summary: loop analysis - Loops 12, 11, 9, 1 plus Loop 2

70. EPAnet loop analysis - Loops 12, 11, 9, 1 plus Loop 3

71. Output summary: loop analysis - Loops 12, 11, 9, 1 plus Loop 3

72. EPAnet loop analysis - Loops 12, 11, 9, 1 plus Loop 4

73. Output summary: loop analysis - Loops 12 , 11, 9, 1 plus Loop 4

74. EPAnet loop analysis - Loops 12, 11, 9, 1 plus Loop 5

75. Output summary: loop analysis - Loops 12, 11, 9, 1 plus Loop 5

76. EPAnet loop analysis - Loops 12, 11, 9, 1 plus Loop 6

77. Output summary: loop analysis - Loops 12, 11, 9, 1 plus Loop 6

78. EPAnet loop analysis - Loops 12, 11, 9, 1 plus Loop 7

79. Output summary: loop analysis - Loops 12, 11, 9, 1 plus Loop 7

80. EPAnet loop analysis - Loops 12, 11, 9, 1 plus Loop 8

81. Output summary: loop analysis - Loops $12,11,9$, 1 plus Loop 8 
82. EPAnet loop analysis - Loops 12, 11, 9, 1 plus Loop 10

83. Output summary: loop analysis- Loops $12,11,9,1$ plus Loop 10

Files 84-97 are for the analysis after installing Loops 12, 11, 9, 1 and 5. Used to determine which loop ranked \#5:

84. EPAnet loop analysis - Loops 12, 11, 9, 1, 5 plus Loop 2

85. Output summary: loop analysis - Loops $12,11,9,1,5$ plus Loop 2

86. EPAnet loop analysis - Loops 12, 11, 9, 1, 5 plus Loop 3

87. Output summary: loop analysis - Loops 12, 11, 9, 1, 5 plus Loop 3

88. EPAnet loop analysis - Loops 12, 11, 9, 1, 5 plus Loop 4

89. Output summary: loop analysis - Loops $12,11,9,1,5$ plus Loop 4

90. EPAnet loop analysis - Loops 12, 11, 9, 1, 5 plus Loop 6

91. Output summary: loop analysis - Loops 12, 11, 9, 1, 5 plus Loop 6

92. EPAnet loop analysis - Loops 12, 11, 9, 1, 5 plus Loop 7

93. Output summary: loop analysis - Loops $12,11,9,1,5$ plus Loop 7

94. EPAnet loop analysis - Loops 12, 11, 9, 1, 5 plus Loop 8

95. Output summary: loop analysis - Loops $12,11,9,1,5$ plus Loop 8

96. EPAnet loop analysis - Loops 12, 11, 9, 1, 5 plus Loop 10

97. Output summary: loop analysis - Loops 12,11 , 9, 1, 5 plus Loop 10

Files 98-109 are for the analysis after installing Loops 12, 11, 9, 1, 5 and 8. Used to determine which loop ranked \#6:

98. EPAnet loop analysis - Loops 12, 11, 9, 1, 5, 8 plus Loop 2

99. Output summary: loop analysis - Loops $12,11,9,1,5,8$ plus Loop 2

100. EPAnet loop analysis - Loops $12,11,9,1$, 5, 8 plus Loop 3

101. Output summary: loop analysis - Loops $12,11,9,1,5,8$ plus Loop 3 
102. EPAnet loop analysis - Loops $12,11,9,1,5,8$ plus Loop 4

103. Output summary: loop analysis - Loops $12,11,9,1,5,8$ plus Loop 4

104. EPAnet loop analysis - Loops 12, 11, 9, 1, 5, 8 plus Loop 6

105. Output summary: loop analysis - Loops $12,11,9,1,5,8$ plus Loop 6

106. EPAnet loop analysis - Loops $12,11,9,1,5,8$ plus Loop 7

107. Output summary: loop analysis - Loops $12,11,9,1,5,8$ plus Loop 7

108. EPAnet loop analysis - Loops 12, 11, 9, 1, 5, 8 plus Loop 10

109. Output summary: loop analysis - Loops $12,11,9,1$, 5, 8 plus Loop 10

Files 110-119 are for the analysis after installing Loops $12,11,9,1,5,8$ and 3 . Used to determine which loop ranked \#7:

110. EPAnet loop analysis - Loops 12, 11, 9, 1, 5, 8, 3 plus Loop 2

111. Output summary: loop analysis - Loops 12, 11, 9, 1, 5, 8, 3 plus Loop 2

112. EPAnet loop analysis - Loops 12, 11, 9, 1, 5, 8, 3 plus Loop 4

113. Output summary: loop analysis - Loops $12,11,9,1,5,8,3$ plus Loop 4

114. EPAnet loop analysis - Loops 12, 11, 9, 1, 5, 8, 3 plus Loop 6

115. Output summary: loop analysis - Loops 12,11 , 9, 1, 5, 8, 3 plus Loop 6

116. EPAnet loop analysis - Loops $12,11,9,1$, 5, 8, 3 plus Loop 7

117. Output summary: loop analysis - Loops 12,11 , 9, 1, 5, 8, 3 plus Loop 7

118. EPAnet loop analysis - Loops 12, 11, 9, 1, 5, 8, 3 plus Loop 10

119. Output summary: loop analysis - Loops 12,11 , 9, 1, 5, 8, 3 plus Loop 10

Files 120-127 are for the analysis after installing Loops $12,11,9,1,5,8,3$ and 2 . Used to determine which loop ranked \#8:

120. EPAnet loop analysis - Loops 12, 11, 9, 1, 5, 8, 3, 2 plus Loop 4

121. Output summary: loop analysis - Loops $12,11,9,1,5,8,3,2$ plus Loop 4 
122. EPAnet loop analysis - Loops 12, 11, 9, 1, 5, 8, 3, 2 plus Loop 6

123. Output summary: loop analysis - Loops 12, 11, 9, 1, 5, 8, 3, 2 plus Loop 6

124. EPAnet loop analysis - Loops 12, 11, 9, 1, 5, 8, 3, 2 plus Loop 7

125. Output summary: loop analysis - Loops 12, 11, 9, 1, 5, 8, 3, 2 plus Loop 7

126. EPAnet loop analysis - Loops 12, 11, 9, 1, 5, 8, 3, 2 plus Loop 10

127. Output summary: loop analysis - Loops 12, 11, 9, 1, 5, 8, 3, 2 plus Loop 10

Files 128-133 are for the analysis after installing Loops $12,11,9,1,5,8,3,2$ and 7 . Used to determine which loop ranked \#9:

128. EPAnet loop analysis - Loops 12, 11, 9, 1, 5, 8, 3, 2, 7 plus Loop 4

129. Output summary: loop analysis - Loops $12,11,9,1,5,8,3$, 2, 7 plus Loop 4

130. EPAnet loop analysis - Loops 12, 11, 9, 1, 5, 8, 3, 2, 7 plus Loop 6

131. Output summary: loop analysis - Loops 12,11 , 9, 1, 5, 8, 3, 2, 7 plus Loop 6

132. EPAnet loop analysis - Loops 12, 11, 9, 1, 5, 8, 3, 2, 7 plus Loop 10

133. Output summary: loop analysis - Loops 12,11 , 9, 1, 5, 8, 3, 2, 7 plus Loop 10

Files 134-137 are for the analysis after installing Loops 12, 11, 9, 1, 5, 8, 3, 2, 7 and 6 . Used to determine which loop ranked \#10:

134. EPAnet loop analysis - Loops 12, 11, 9, 1, 5, 8, 3, 2, 7 plus Loop 4

135. Output summary: loop analysis - Loops $12,11,9,1$, 5, 8, 3, 2, 7 plus Loop 4

136. EPAnet loop analysis - Loops 12, 11, 9, 1, 5, 8, 3, 2, 7 plus Loop 10

137. Output summary: loop analysis - Loops 12,11 , 9, 1, 5, 8, 3, 2, 7 plus Loop 10

138. EPAnet Loop analysis - all Loops: Medina Bank simulation with all 12 Loops installed. 48 hour simulation.

139. Loop analysis- all loops output summary 